\title{
Tolosa-Hunt Syndrome Revisited: Not Necessarily a Diagnosis of Exclusion
}

\author{
Eddie S. K. Kwan ${ }^{1}$ \\ Samuel M. Wolpert ${ }^{1}$ \\ Thomas R. Hedges III \\ Michael Laucella ${ }^{1}$
}

\footnotetext{
This article appears in the November/December 1987 issue of AJNR and the February 1988 issue of $A J R$.

Received February 5, 1987; accepted after revision June 10, 1987.

'Department of Radiology, New England Medical Center, 171 Harrison Ave., Boston, MA 02111. Address reprint requests to $\mathrm{E}$. S. K. Kwan.

${ }^{2}$ Section of Neuroophthalmology, New England Medical Center, Boston, MA 02111.

AJNR 8: 1067-1072, November/December 1987 0195-6108/87/0806-1067

(c) American Society of Neuroradiology
}

The Tolosa-Hunt syndrome (THS), a steroid-responsive painful ophthalmoplegia secondary to idiopathic granulomatous inflammation, historically has been categorized as a diagnosis of exclusion because of its nonspecific radiologic presentation. Five patients who satisfied the anatomic and clinical criteria of this syndrome underwent highresolution $\mathrm{CT}$ of the orbital apex/cavernous sinus region. Two patients were diagnosed as having orbital apex pseudotumor, two as having cavernous sinus inflammation, and one as having a cavernous sinus epidermoid by the characteristic CT and clinical findings. Follow-up studies while the patients were asymptomatic demonstrated complete resolution of the $\mathrm{CT}$ abnormalities in four patients and clinical improvement in all five patients.

Our data suggest that orbital apex pseudotumor and granulomatous inflammation of the cavernous sinus have similar clinical features and should be considered as part of the spectrum of THS. With the advent of high-resolution CT, THS may now be a diagnosis of inclusion. Symptomatic improvement after steroid therapy is an essential but not absolute proof of the syndrome, since lesions such as lymphomas may also respond to steroids. Resolution of the soft-tissue inflammation on CT is an additional criterion for diagnosis.

The hallmark of the Tolosa-Hunt syndrome (THS) is a painful ophthalmoplegia that is steroid responsive. In 1954, Tolosa [1] reported a patient with left orbital pain, ipsilateral progressive visual loss, total left ophthalmoplegia, and hypesthesia over the first division of the trigeminal nerve. Cerebral angiography demonstrated narrowing of the intracavernous segment of the left internal carotid artery; at autopsy, a low-grade nonspecific granulomatous inflammation of the cavernous sinus and adventitia of the carotid artery was identified. In 1961, Hunt et al. [2] reported six cases of remittent unilateral retroorbital pain accompanied by extraocular palsies and occasional supraorbital numbness and blindness; these patients also improved promptly on corticosteroids. Since the radiologic findings of THS in the pre-CT era were often nonspecific and the symptom complex of painful ophthamoplegia could be clinically encountered in patients with other disorders (aneurysms, diabetes mellitus, periarteritis nodosa, parasellar neoplasm/infection, cavernous sinus thrombosis, and carotid cavernous fistula), there has been a strong emphasis in the neurologic and ophthalmologic literature to categorize the THS as a diagnosis of exclusion. With the advent of high-resolution CT, lesions located in the orbital apex, superior orbital fissure, and cavernous sinus region that are directly responsible for the symptoms can now be imaged. As a result, we no longer believe that the THS is a diagnosis of exclusion. While the syndrome is often considered a benign, self-limiting entity, permanent damage to the involved cranial nerves can occur, making prompt diagnosis and steroid therapy mandatory. It is also important that the radiologist be aware of the spectrum of CT findings in this syndrome to obviate surgical exploration. The clinical and radiologic findings in five patients who satisfy the criteria of THS are the subject of this report. 


\section{Materials and Methods}

Between 1981 and 1986, five patients with THS were evaluated by the neuroophthalmology and neuroradiology sections at our institution. All patients underwent high-resolution 2-mm contrast-enhanced $\mathrm{CT}^{*}$ of the orbit and parasellar regions as a part of the diagnostic evaluation of painful ophthalmoplegia. Tissue diagnosis was obtained in one patient. A dramatic response to steroid therapy accompanied either by resolution of the $\mathrm{CT}$ abnormality or by longterm follow-up established the diagnosis of THS in the remaining four patients.

\section{Case Reports}

\section{Case 1}

A 22-year-old white man with a 12-year history of Crohn disease developed bifrontal constant headache accompanied by nausea, numbness of the right upper lip, and diplopia on left lateral and upward gaze 2 weeks before admission. The pain was more severe over his right eye. Physical examination showed normal visual acuity, minimal ptosis of the right upper eyelid, and decreased adduction of the right eye. Pertinent laboratory data included a normal lumbar puncture, sedimentation rate, WBC count, and fasting blood glucose. Antinuclear antibody and rheumatoid factors were negative. The patient underwent high-resolution contrast-enhanced CT through the parasellar region (Fig. 1A).

Since the cause of the diplopia and headache was not clear and the implication of the enlarged right cavenous sinus was not fully appreciated at the time, the headache was treated symptomatically. Over the next 2 weeks, the patient noted increasing horizontal and oblique diplopia. A repeat ophthalmologic examination (now 5 weeks after the onset of symptoms) demonstrated a pupil-sparing thirdnerve palsy and a complete fifth-nerve dysfunction. Owing to the patient's age, the lack of bony involvement, and the clinical course, an inflammatory process was considered more likely than malignancy. A therapeutic trial of prednisone was started at $60 \mathrm{mg} /$ day. The patient's headache, ptosis, diplopia, and hypesthesia in the trigeminal distribution responded dramatically within $48 \mathrm{hr}$, and resolution was complete within 1 week. Follow-up CT demonstrated a normalappearing right cavernous sinus (Fig. 1B).

\section{Case 2}

A healthy 24-year-old white man developed sudden onset of right retrobulbar pain relieved by aspirin 3 weeks before admission. A complete right third nerve palsy was noted over the next several days. A CT brain scan and bilateral carotid angiography at another institution were reported as normal. Since diabetes, parasellar tumor, and posterior communicating artery aneurysms had apparently been excluded, he was started empirically on methyl prednisolone, $24 \mathrm{mg} /$ day to be tapered over a 1-week period. This relieved the headache almost immediately, but the diplopia persisted. Pertinent findings on ophthalmologic examination at our institution included normal visual acuity, ptosis of the right upper eyelid, a poorly reactive dilated right pupil, reduced ocular motility in the direction of all the muscles supplied by the right third nerve, and mild impairment of the motor division of the right fifth nerve. A repeat CT scan of the parasellar region demonstrated a low attenuating mass in the right cavernous sinus (Fig. 2). When steroids were restarted, the patient noted marked improvement of his retrobulbar pain, pupillary functions, and extraocular movements. As the steroids were tapered, there was a mild

\footnotetext{
- Siemen's Somatom 2 or DR3.
}

flare-up of the headache and the ptosis. The working diagnosis was leakage from an epidermoid tumor in the right cavernous sinus with secondary inflammation.

\section{Case 3}

A 26-year-old previously healthy black man experienced 2 weeks of generalized fatigue, fever, and night sweats 8 weeks before admission. By 6 weeks before admission, the patient experienced diplopia on left lateral gaze and left retroorbital pain. Pertinent physical findings on admission included visual acuity of 20/25 on the right and $20 / 60$ on the left, a left relative afferent pupillary defect, left lateral rectus dysfunction, hypesthesia over the first division of the left trigeminal nerve, and bilateral inguinal adenopathy. Laboratory studies including lumbar puncture and serology were noncontributory. CT and MR of the brain and parasellar region demonstrated multiple bilateral parenchymal and dural-based lesions (Figs. 3A-3D). The leading differential diagnoses were CNS sarcoidosis and lymphoma. Subsequent chest films and CT scans demonstrated paratracheal, paraaortic, and perihilar adenopathy. A mediastinal lymph-node biopsy showed noncaseating granulomata compatible with sarcoidosis. Visual acuity deteriorated to $20 / 200$ over a 10 -day period. The patient was subsequently started on methyl prednisolone, $60 \mathrm{mg}$ every $6 \mathrm{hr}$, then changed to oral prednisone, $80 \mathrm{mg}$ every morning. Visual acuity on the left transiently improved to $20 / 30$; headache, facial paresthesias, and diplopia all resolved within several days. When the patient prematurely discontinued the prednisone, visual acuity of the left eye deteriorated to $20 / 400$ with the development of a central scotoma. High-dose IV methyl prednisone was therefore administered for a 5day period followed by oral prednisone. Follow-up CT 8 weeks later demonstrated resolution of all intracranial lesions including the cisternal lesion (Fig. 3E). However, visual acuity on the left side did not improve.

\section{Case 4}

A 25-year-old healthy white woman developed diplopia on left lateral gaze several days after an "upper respiratory infection." An orbital CT scan at an outside institution was reported as normal. The deficit remained stable for 1 month until 3 weeks before admission when the patient noted loss of color vision in the left eye and right frontal and left supraorbital headache with radiation to the left occiput. Pertinent findings on ophthalmologic examination at our institution included ptosis and swelling of the left upper lid, minimal proptosis, a left-sided relative afferent pupillary defect, and visual acuity of 20 / 400 on the left. Extraocular movements of the left eye had decreased in all fields of gaze, especially medially. Laboratory studies including thyroid function tests were normal. CT of the orbit was performed (Figs. 4A and 4B). The clinical diagnosis was orbital apex pseudotumor. The patient was initially treated with prednisone, $100 \mathrm{mg} /$ day, but the lack of response necessitated a change to dexamethasone, $20 \mathrm{mg}$ IV every $6 \mathrm{hr}$. The diplopia and retroorbital pain subsequently resolved, while the visual acuity in the left eye improved to $20 / 50$ over the next several days. Follow-up CT 1 week later demonstrated a normal orbital apex (Fig. 4C).

\section{Case 5}

A 62-year-old black man was initially evaluated at our institution 5 years ago for throbbing temporal/retroorbital headache, proptosis, decreased visual acuity, hypesthesia in the V1 and V2 distributions, and third and sixth cranial nerve palsies all localized on the left side. Extensive evaluation included serology, antinuclear antibody, lupus 


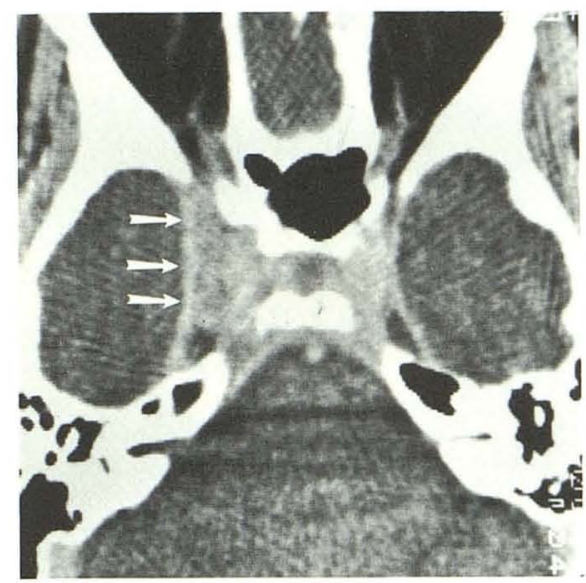

A

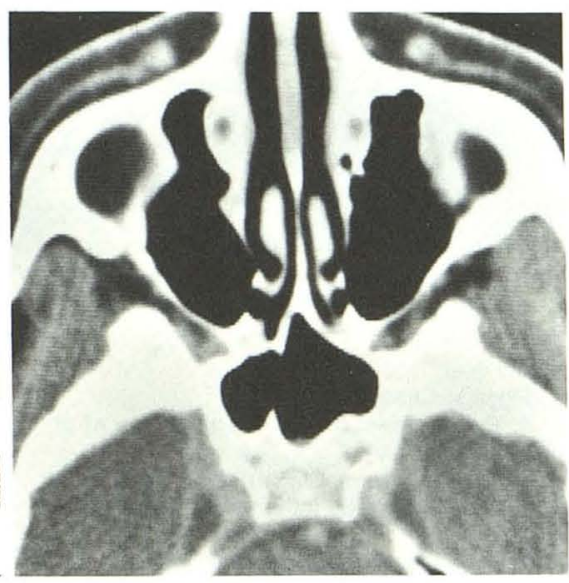

B

Fig. 1.-Case 1.

A, Axial parasellar CT scan shows asymmetric enlargement of right cavernous sinus (arrows) before steroid therapy.

$B$, Follow-up CT scan 7 months later shows normal-appearing cavernous sinus bilaterally.

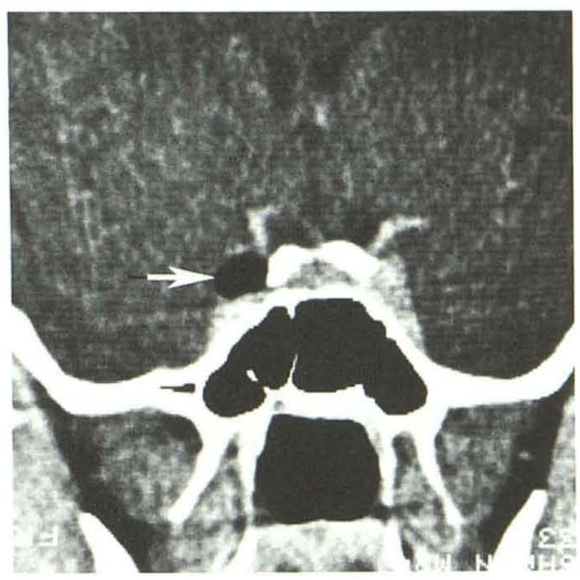

Fig. 2.-Case 2: direct coronal CT scan of parasellar region. Low-density mass within right cavernous sinus (arrow) measures $-87 \mathrm{H}$.

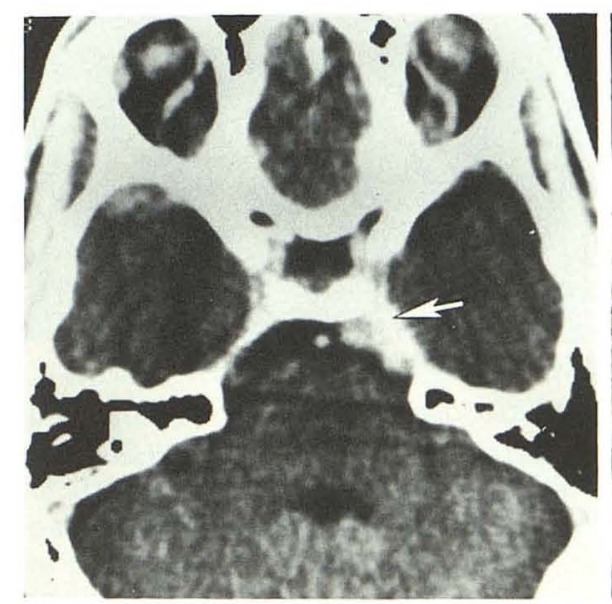

A

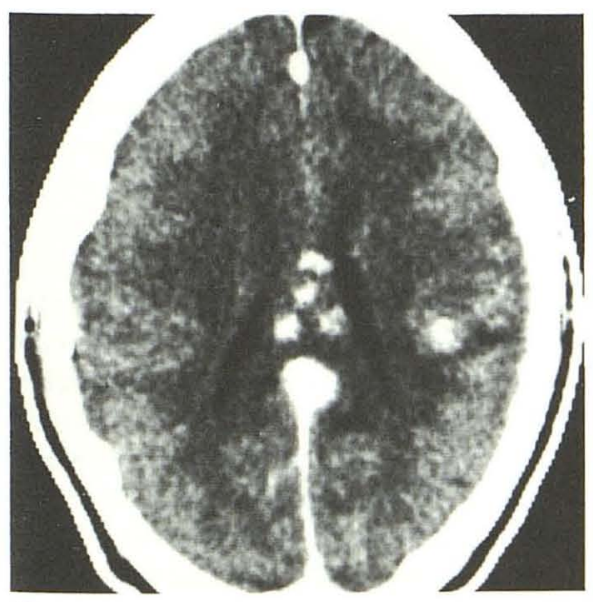

C



B

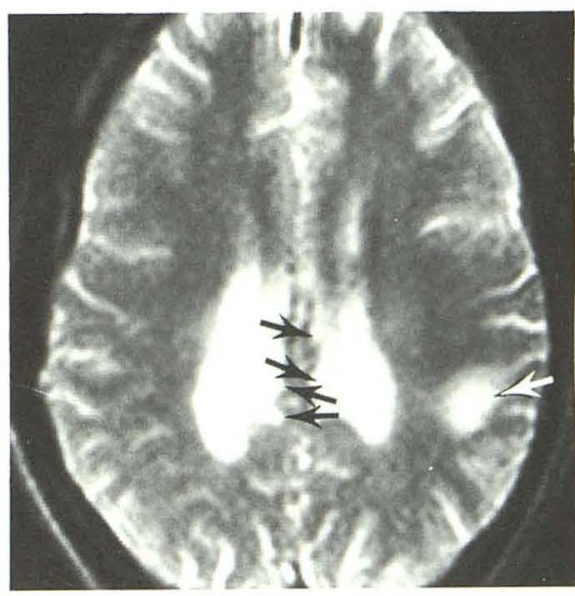

D
Fig. 3.-Case 3: 26-year-old black man.

A, Axial CT scan shows abnormal enhancement in left prepontine cistern (arrow).

$B, 3-\mathrm{mm}$ T1-weighted spin-echo image (TR = $600 \mathrm{msec}, \mathrm{TE}=17 \mathrm{msec}$ ) through same region shows abnormal soft tissue infiltrating posterior cavernous sinus (small black arrow), resulting in anterior displacement of left internal carotid artery (large black arrow) and effacement of fat within cavernous sinus. Note fat within right cavernous sinus (white arrow).

$C$, Multiple parenchymal enhancing lesions in corpus callosum and left parietal lobe.

$D, T 2$-weighted spin-echo image at same level shows multiple lesions with prolonged T2 in corpus callosum and left centrum semiovale (arrows).

$E$, Cavernous sinuses are now symmetric, and abnormal enhancement in prepontine cistern has resolved after high-dose steroid therapy. 


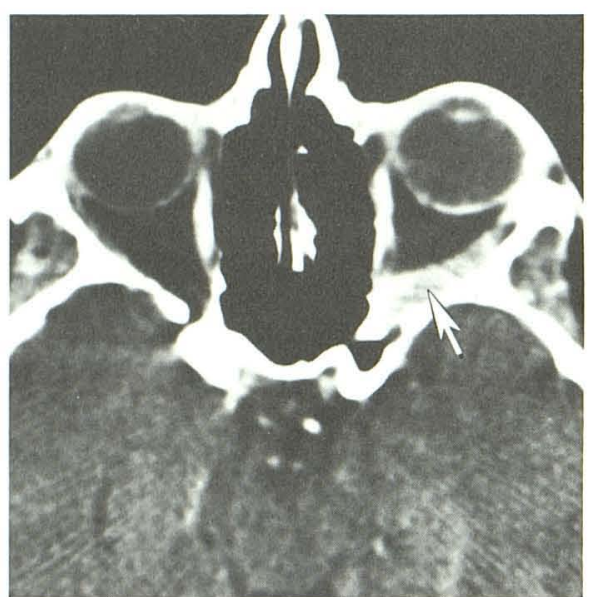

A

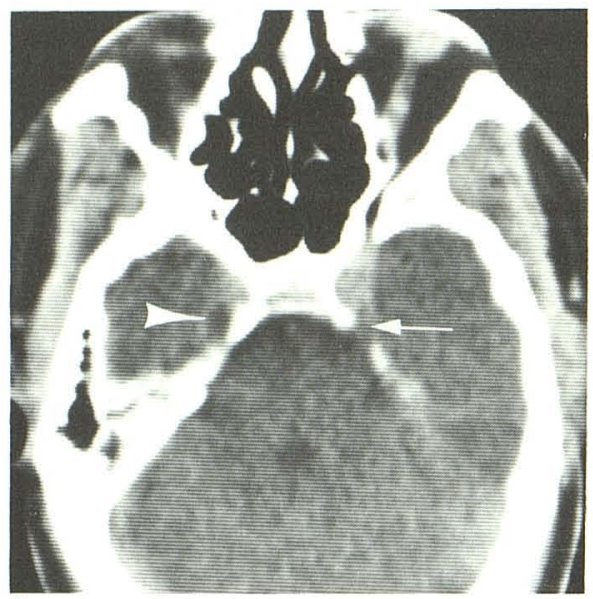

A

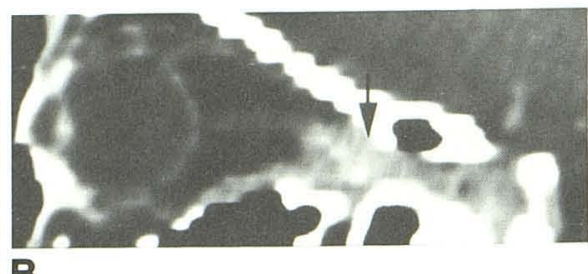

B

Fig. 4.-Case 4

A, Enlargement of left lateral rectus at orbital apex (arrow).

$B$, Sagittal reformatting shows compression of left optic nerve by inflammatory soft tissue at apex.

C, After steroid therapy. Left lateral muscle is normal.

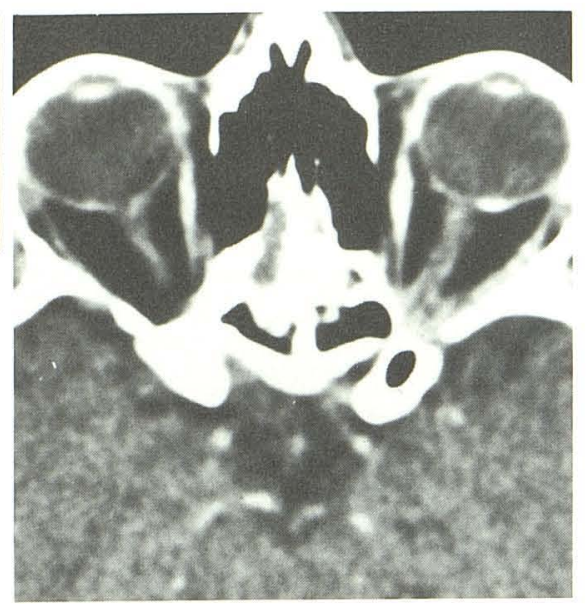

C

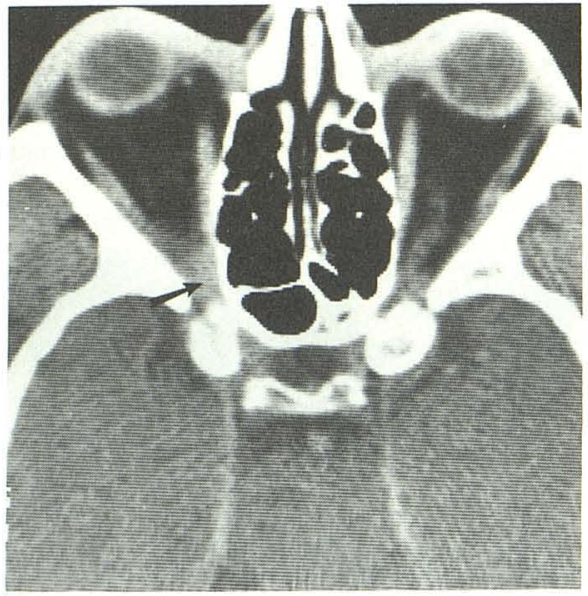

B

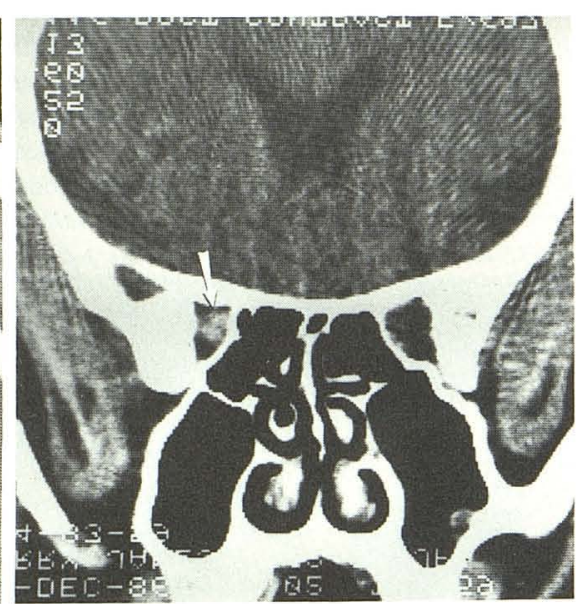

C

Fig. 5.-Case 5.

A, 4-mm axial CT scan through cavernous sinus shows effacement of left Meckel cave (arrow). Note normal Meckel cave (arrowhead) on right side of patient.

$B, 5$ years later. Subtle but definite abnormal soft-tissue mass compresses right orbital apex (arrows) on both axial (B) and coronal (C) views.

erythematosus test, complete blood cell count, fungal and acid-fast bacillus culture of the CSF, cerebral angiography, and temporal artery biopsy; all were negative.

CT of the parasellar region demonstrated partial effacement of the left Meckel cave (Fig. 5A). The major differential diagnoses were occult neoplasm vs idiopathic granulomatous inflammation of the left cavernous sinus. The patient was treated with a tapering dose of oral prednisone starting with $100 \mathrm{mg} /$ day. The headache improved dramatically within $24 \mathrm{hr}$, while the cranial nerve deficits improved gradually over the next 4 weeks. He remained symptom-free for 5 years until he had a 5-day period of diplopia, retroorbital pain, and decreased visual acuity on the right that prompted his current evaluation. Pertinent findings on ophthalmologic examination included decreased visual acuity to finger counting at $1 \mathrm{~m}$ on the right with normal visual acuity on the left, a relative afferent pupillary defect, and third and sixth cranial nerve palsies on the right. CT of the orbit was compatible with apical orbital pseudotumor (Fig. 5B). There was subjective improvement of the diplopia and the retroorbital pain within
$48 \mathrm{hr}$ after initiation of oral prednisone of $100 \mathrm{mg} /$ day. The visual acuity returned to $20 / 25$, and there was minimal residual lateral rectus weakness as the steroids were reduced.

\section{Discussion}

Painful ophthalmoplegia secondary to idiopathic granulomatous inflammation of the cavernous sinus or the superior orbital fissure that is steroid responsive was given the eponym Tolosa-Hunt syndrome by Smith and Taxdal [3] in 1966 when they reported five cases of painful ophthalmoplegia and confirmed the importance of therapeutic trials of steroids as a diagnostic test. Two strict sets of criteria have to be satisfied before a patient can be given this diagnosis [4]. The first is anatomic, wherein the neurologic deficits have to be directly confined to structures in the cavernous sinus, superior orbital fissure, or orbital apex. These include cranial nerves II, III, IV, 
TABLE 1: Summary of Clinical Presentations and Radiologic Findings in Patients with Tolosa-Hunt Syndrome

\begin{tabular}{|c|c|c|c|c|c|c|c|c|}
\hline \multirow{2}{*}{$\begin{array}{l}\text { Case } \\
\text { No. }\end{array}$} & \multirow[b]{2}{*}{ Age } & \multirow[b]{2}{*}{ Gender } & \multirow{2}{*}{$\begin{array}{l}\text { Associated } \\
\text { Systemic } \\
\text { Disease }\end{array}$} & \multirow{2}{*}{$\begin{array}{l}\text { Cranial Nerve } \\
\text { Palsies }\end{array}$} & \multirow{2}{*}{$\begin{array}{l}\text { Decreased Visual } \\
\text { Acuity }\end{array}$} & \multicolumn{2}{|l|}{ CT Findings } & \multirow[b]{2}{*}{ Residual Deficit } \\
\hline & & & & & & Before Steroids & $\begin{array}{c}\text { After } \\
\text { Steroids }\end{array}$ & \\
\hline 1 & 22 & $M$ & $\begin{array}{l}\text { Crohn dis- } \\
\text { ease }\end{array}$ & $\begin{array}{l}\text { R III, V com- } \\
\text { plete }\end{array}$ & No & $\begin{array}{l}\text { Enlarged } \mathrm{R} \text { cavernous } \\
\text { sinus }\end{array}$ & Normal & None \\
\hline 2 & 24 & M & None & R III, V motor & No & $\begin{array}{l}\text { Epidermoid in R cavern- } \\
\text { ous sinus }\end{array}$ & No change & $\begin{array}{l}\text { Mild weakness of R } \\
\text { superior rectus }\end{array}$ \\
\hline 3 & 26 & M & Sarcoidosis & L VI, V1 & Yes; L 20/60 & $\begin{array}{l}\text { Enhancement in prepon- } \\
\text { tine cistern, posterior } \\
\text { cavernous sinus, and } \\
\text { brain }\end{array}$ & Normal & $\begin{array}{l}\text { L visual acuity 20/ } \\
400\end{array}$ \\
\hline 4 & 25 & $\mathrm{~F}$ & None & L III, IV, VI & Yes; L 20/400 & $\begin{array}{l}\text { Swelling of } L \text { lateral rec- } \\
\text { tus and inflammation } \\
\text { at orbital apex }\end{array}$ & Normal & $\begin{array}{l}\text { L visual acuity } 20 / \\
50\end{array}$ \\
\hline \multirow[t]{2}{*}{$5^{\mathrm{a}}$} & 57 & M & None & $\begin{array}{l}\text { L III, VI, V1, } \\
\text { V2 }\end{array}$ & Yes; L 20/50 & $\begin{array}{l}\text { Effacement of Meckel } \\
\text { cave }\end{array}$ & Normal & None \\
\hline & 62 & M & - & R III, VI & $\begin{array}{l}\text { Yes; } R \text { finger } \\
\text { counting at } 1 \mathrm{~m}\end{array}$ & $\begin{array}{l}\text { Increased soft tissue in } \\
\mathrm{R} \text { orbital apex }\end{array}$ & Normal & $\begin{array}{l}\text { Mild weakness of } R \\
\text { lateral rectus }\end{array}$ \\
\hline
\end{tabular}

${ }^{\mathrm{a}}$ Two episodes 5 years apart.

Note. $-R=$ right, $L=$ left.

$\mathrm{VI}$, and $\mathrm{V} 1$; parasympathetic pupillodilator fibers of the third nerve; and sympathetic pupilloconstrictor fibers of the pericarotid plexus. Dysfunction of V2 and the motor division of the trigeminal nerve is encountered less often. The second set of criteria relates to the clinical behavior in which "steady" periorbital or retroorbital pain usually precedes but may arise concomitant with the onset of ophthalmoplegia. The symptoms are often relapsing and remitting and can last for days to weeks. Even though the pathologic process is self-limited and spontaneous remissions do occur, a short course of steroids can dramatically relieve the periorbital pain within $24-48 \mathrm{hr}$, followed by gradual resolution of the cranial nerve dysfunctions. The cause of this syndrome is unknown.

While painful ophthalmoplegia is not an uncommon clinical problem, the THS has been considered a rare clinical entity. Thomas and Yoss [5] reported three cases of THS in a review of 102 patients with parasellar syndrome. An additional four patients satisfied the criteria of this syndrome in an analysis of 1000 cases of paralysis involving cranial nerves III, IV, and VI [6]. In a report by Hasso et al. [7] of 131 patients with cavernous sinus syndrome, idiopathic inflammation of the cavernous sinus was not represented. In the most extensive recent review of this topic by Kline [8] in 1982, the author analyzed 146 patients and emphasized that the THS is categorically a diagnosis of exclusion. Since many disease processes (vascular, neoplastic, or inflammatory) located in the region of the cavenous sinus, superior orbital fissure, and orbital apex can produce a similar pattern of pain and neurologic deficit, the concept of the THS as a diagnosis of exclusion was valid at a time when radiologic evaluation lagged behind clinical understanding. The fact that no consistent or specific abnormality can be identified in the hematologic, bacteriologic, and spinal fluid analyses makes the clinical diagnosis of this group of patients even more elusive.

With the exception of an isolated case report [9], CT has been reported to be essentially normal in the majority of patients with THS $[10,11]$. However, erosion of the sella turcica [12], segmental narrowing of the cavernous carotid artery $[1,13,14]$, and occlusion of the superior ophthalmic vein in the orbital apex have been described $[10,13,15$, 16]. Since the efficacy of high-resolution CT in the evaluation of the orbital apex [17] and the cavernous sinus regions [18] has been firmly established, we now believe the pathologic processes responsible for the THS can be imaged directly by $\mathrm{CT}$, and this syndrome is now not a diagnosis of exclusion but a diagnosis of inclusion.

The clinical deficits and CT findings in our five patients with six episodes of steroid-responsive painful ophthalmoplegia are summarized in Table 1. Dysfunction of the trigeminal nerve was seen in cases 1-3 and initially in case 5 . In each case, CT reliably demonstrated abnormalities in either the cavernous sinus, Meckel cave, or along the course of the cisternal segment of the fifth nerve. Decreased visual acuity as a presenting symptom was observed in cases 3-5. Compression of the optic nerve at the orbital apex by pseudotumor and myositis of the lateral rectus can adequately explain the visual impairment of case 5 (second episode) and case 4 . The cause of the decreased visual acuity in case 3 is less obvious. In patients with systemic sarcoidosis, visual impairment most often results from uveitis, retinal detachment, or vitreous hemorrhage [19]. While granulomatous infiltration of sarcoid in the orbital apex and enlargement of the optic nerve have been reported [19-21], they are considered rare phenomena, and were not seen on the scans in case 3. The lack of improvement in visual acuity in this patient after high-dose steroids make retrobulbar neuritis or microscopic infiltration of sarcoid within the optic nerve an unlikely cause of visual impairment, especially in the context that all previously visible CNS lesions resolved on follow-up CT and MR. We speculate that the optic neuropathy in this patient may be secondary to sarcoid angiopathy. Of the five patients in our series, this patient suffered the most severe sequelae, which reemphasizes that, although THS is a self-limiting disease, it can lead to irreversible damage. 
CT findings remarkably similar to those in our case 2 have been reported by Kline and Galbraith [9]. Surgical exploration in their case revealed an epidermoid cyst. While we did not have pathologic proof in our case, we believe leakage of the epidermoid contents into the cavernous sinus resulted in an aseptic inflammatory response.

The myositic and orbital apex involvement by pseudotumor [22] in cases 4 and 5 (second episode) represents a different subset of THS - a concept that we believe has not been emphasized in the radiologic literature. The orbital apex, superior orbital fissure, and anterior cavernous sinus are contiguous; granulomatous inflammation in any of the three locations will produce similar symptoms. Granulomatous tissue from orbital pseudotumor and from the cavernous sinus of patients reported by Tolosa [1] and others [23-25] has characteristically demonstrated numerous plasma cells and lymphocytes. Since both subsets of patients respond promptly to steroids, it is both logical and clinically useful to consider orbital apex pseudotumor as part of the spectrum of THS. Clinically, patients with orbital pseudotumor have a higher propensity than do patients with cavernous sinus lesions to present with proptosis, chemosis, and conjunctival injection.

High-resolution CT in patients with THS usually demonstrates soft-tissue infiltration in either the orbital apex or the cavernous sinus with no associated bony destruction on hyperostosis. The contour of the involved cavernous sinus in patients with THS usually has a slightly concave lateral margin in contrast to aneurysm or neuroma, which has a laterally convex margin. The enhancement in THS is less prominent compared with giant cavernous carotid aneurysm or meningioma. THS also can be differentiated from cavernous sinus thrombosis and carotid cavernous fistula by the absence of an enlarged superior ophthalmic vein. The infiltrating mass as a rule resolves after the administration of steroids. Symptomatic improvement following short-term steroids in a patient with painful ophthalmoplegia is an essential clinical feature of THS. The improvement, however, is not absolute proof of the diagnosis, because lymphoma, meningioma, and giant cell tumors have also been reported to respond symptomatically to high-dose steroids initially [5, 26]. Likewise, orbital lymphoma can transiently resolve on CT after steroid therapy.

In conclusion, with the advent of high-resolution CT scanning, abnormal inflammatory soft tissue in both the orbital apex and cavernous sinus directly responsible for painful ophthalmoplegia can now be imaged. As a result, THS can no longer be considered a diagnosis of exclusion. We would like to propose that resolution of soft-tissue inflammation in the orbital apex and cavernous sinus on CT while a patient is asymptomatic and not taking steroids should be an additional clinical criterion of THS. Surgical exploration should rarely be necessary for inflammatory disease in this region unless highdose steroid therapy fails and there is progressive neurologic deficit and pain.

\section{REFERENCES}

1. Tolosa E. Periarteritic lesions of the carotid siphon with the clinical features of a carotid infraclinoid aneurysm. I Neurol Neurosurg Psychiatry 1954;17:300-302

2. Hunt WE, Meagher JN, LeFever HE, Zeman W. Painful ophthalmoplegia. Its relation to indolent inflammation of the cavernous sinus. Neurology 1961;11:56-62

3. Smith JL, Taxdal DSR. Painful ophthalmoplegia. The Tolosa-Hunt syndrome. Am J Ophthalmol 1966;61:1466-1472

4. Hunt WE. Tolosa-Hunt syndrome: one cause of painful ophthalmoplegia. $J$ Neurosurg 1976;44:544-549

5. Thomas JE, Yoss RE. The parasellar syndrome: problems in determining etiology. Mayo Clin Proc 1978;45:617-623

6. Rush JA, Younge BR. Paralysis of cranial nerves III, IV and VI. Arch Ophthalmol 1981;99:76-79

7. Hasso AN, Pop PM, Thompson JR, et al. High resolution thin section computed tomography of the cavernous sinus. Radiographics 1982;2:83100

8. Kline LB. The Tolosa-Hunt syndrome. Surv Ophthalmol 1982;27:79-95

9. Kline LB, Galbraith JG. Parasellar epidermoid tumor presenting as painful ophthalmoplegia. J Neurosurg 1981;54:113-117

10. Aron-Rosa D, Doyon D, Salamon G, Michotey P. Tolosa-Hunt syndrome. Ann Ophthalmol 1978;10:1161-1168

11. Van Dalen JTW, Bleeker GM. The Tolosa-Hunt syndrome. Doc Ophthalmol 1977; $44: 167-172$

12. Polsky M, Janicki PC, Gunderson $\mathrm{CH}$. Tolosa-Hunt syndrome with sella erosion. Ann Neurol 1979;6:129-131

13. Sondheimer FK, Knapp J. Angiographic findings in the Tolosa-Hunt syndrome: painful ophthalmoplegia. Radiology 1973;106:105-112

14. Kettler HL, Martin JD. Arterial stationary wave phenomenon in Tolosa Hunt syndrome. Neurology 1975;25:765-770

15. Milstein BA, Morretin LB. Report of a case of sphenoid fissure syndrome studied by orbital venography. Am J Ophthalmol 1971;72:600-603

16. Muhletaler CA, Gerlock AJ. Orbital venography in painful ophthalmoplegia (Tolosa-Hunt syndrome). AJR 1979;133:31-34

17. Daniels DL, Pech $P$, Kay MC, Pojunas K, Williams AL, Haughton VM Orbital apex: correlative anatomic and CT study. AJNR 1985;6:705-710

18. Kline LB, Acker JD, Post MJD, Vitek JJ. The cavernous sinus: a computed tomographic study. AJNR 1981;2:299-305

19. Beardsley TL, Brown SVL, Sydnor CF, Grimson BS, Klintworth GK. Eleven cases of sarcoidosis of the optic nerve. Am J Ophthalmol 1984;97:62-77

20. Gudeman SK, Selhorst JB, Susac JO, Waybright EA. Sarcoid optic neuropathy. Neurology 1982;32:597-603

21. Dubois PJ, Beardsley T, Klintworth G, et al. Computed tomography of sarcoidosis of the optic nerve. Neuroradiology 1983;24:179-182

22. Nugent RA, Rootman J, Robertson WD, Lapointe JS, Harrison PB. Acute orbital pseudotumors: classification and CT features. AJNR 1981;2:431436

23. Hallpike JF. Superior orbital fissure syndrome. J Neurol Neurosurg Psychiatry 1973;36:486-490

24. Donin JF, Borit A. Orbital myositis: its relationship to the Tolosa-Hunt syndrome. In: Smith JL, ed. Neuro-ophthalmology update. New York City: Masson, 1977:99-103

25. Levy IS, Wright JE, Lloyd GAS. Orbital and retroorbital pseudotumors. Mod Probl Ophthalmol 1975;14:364-357

26. Fowler TJ, Earl CJ, McAllister VL, McDonald WI. Tolosa-Hunt syndrome. The dangers of an eponym. Br J Ophthalmol 1975;59:149-154 